$$
\text { تاثير النقع و الانبات في التركيب التقريبي وخاصيتي الذوبانية ودرجة التحلل للبروتينات }
$$

\title{
Effect of soaking and germination on approximate composition and certain characterize of isolate protein (solubility and degree of hydrolysis) Of mung bean Vigna radiate
}

\author{
مصطفى جمعة فرحان \\ Abdul kadir Hadi Alwan \\ وزارة العلوم وبيح مطثنر لتوجيا \\ عبد القادر هادي علوان \\ Sahr Sebeh \\ Mustafa Farhan Guma \\ Ministry of Science and Technology
}

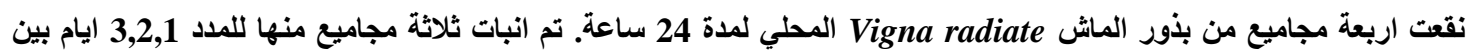

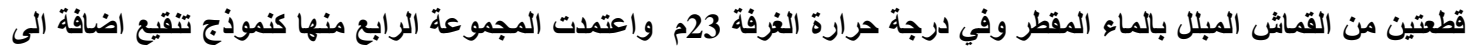

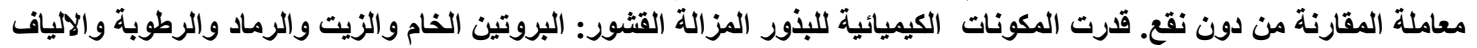

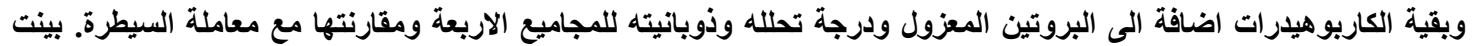
نتائج التحليل الكيميائي لمعاملة السيطرة ان نسبة البروتين الخام بلغت 23.53 و 23.

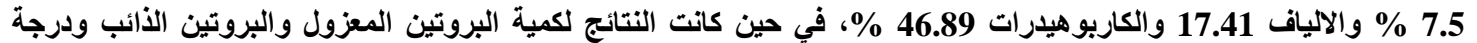

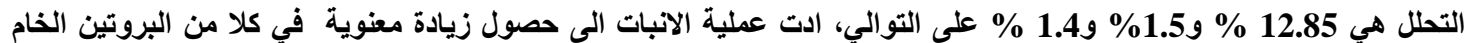
والبروتين المغزول ودرجة التحلل و بلغت اقصاها في اليوم الثاني من الانبات و بلغت 25.29 و و15.34 و2.11.

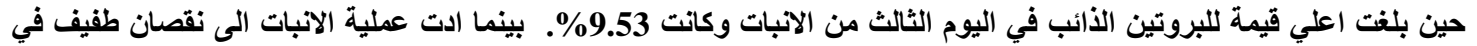

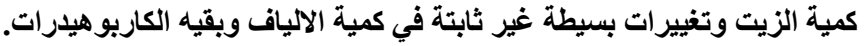

$$
\text { الكلمات المفتاحية: الانبات، الماش، البروتينات المعزولة }
$$

\section{Abstract:}

Four groups of local mung bean Vigna radiate were soaked for $24 \mathrm{~h}$. Three of these were germinated for 1,2 and 3 days at room temperature $23^{\circ}$ Cusing wet cloths between technique while the fourth was depending as a soaking sample in addition to control treatment without soaking. Approximate chemical composition (crud protein, oil, ash, moisture, fibers and carbohydrates) and mung protein isolates (MPI) with its solubility SP and degree of hydrolysis DH, were determined for four dehulling groups besides control sample. Dehulling mung bean DMB flour contained 23.53, 1.83, 3.11, 7.5, 17.14 and 46.89\% crud protein, oil, ash, moisture, fibers and carbohydrates, respectively. While the values of MPI, SP, and DH were 12.85, 1.5 and $1.4 \%$ respectively .During germination significantly increasing in (CP) (MPI) and (DH) and the maximum values were $25.29,15.34$ and $2.11 \%$ respectively after two days, while maximum value was $9.53 \%$ for protein solubility after 3 days of germination. While oil content diminished a little and slight inconstant changes were shown in fibers and rest carbohydrates.

Key words: germination, mung bean, isolate protein

تعد عائلة البقوليات Fabaceae من العوائل النباتية المهمة كونها تشمل اعدادا كبيرة من المحاصيل الحقلية الاقتصادية منها الباقلاء

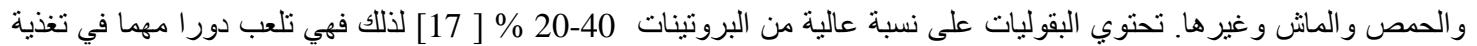

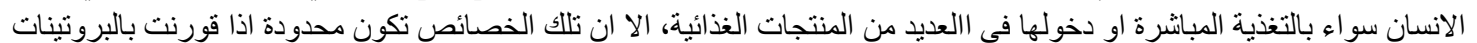

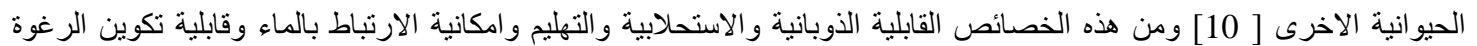

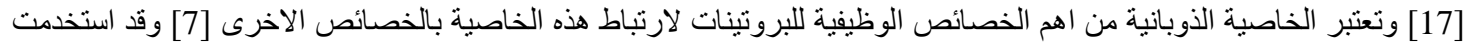

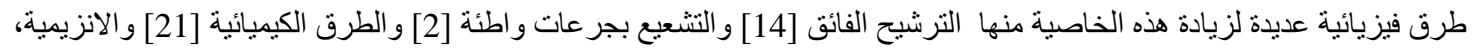

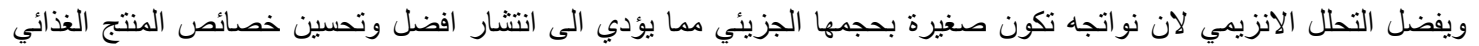

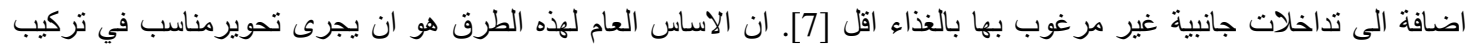

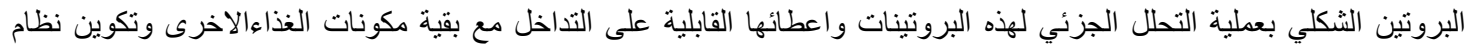

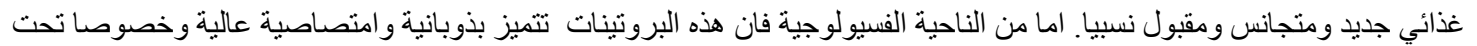

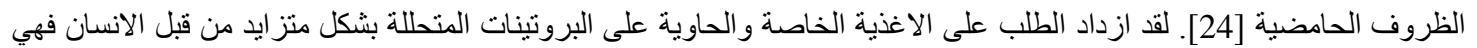

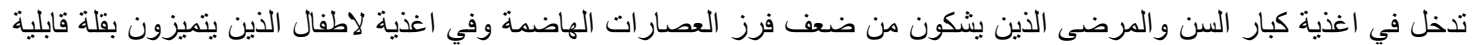

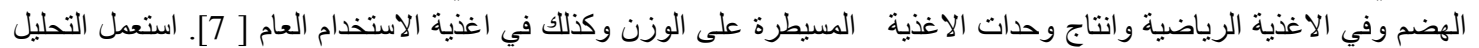

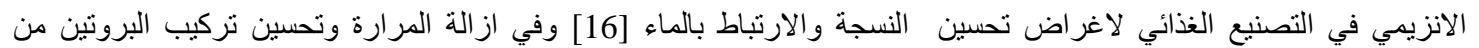


الحوامض الامينيه [18]. يسلط هذا البحث الضوء على اثر الانبات على التركيب الثقريبي وخاصيتي الذوبانية ودرجة التحلل اللبروتينات المعزولة من بذور الماش المز الة المبنة القشور.

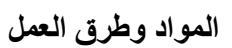
استعملت البذور الناضجة من الماثل والتي نم الحصول عليها من السوق المحلية وتم استبعاد الذذور الغريية و الاوساخ و الاتربة،واعتمدت البذور الناضجة و غنلت بالماء المقطر.

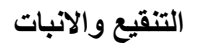

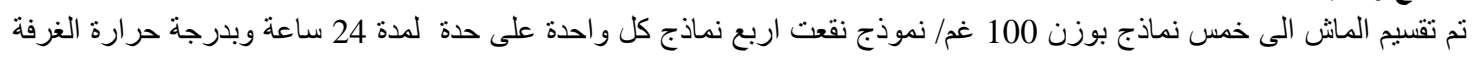

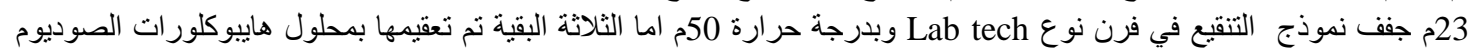

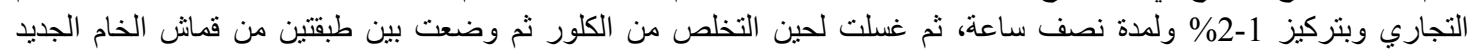

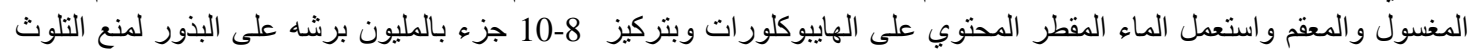

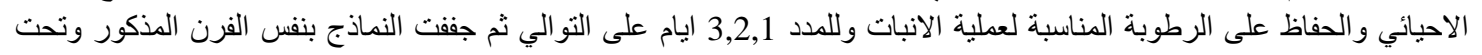

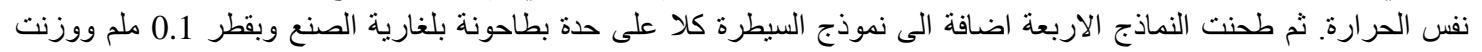

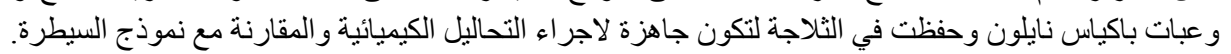

التحاليل الكيميائية تم قياس النسبة المئوية للبروتين والزيت والرطوبة والرماد في نماذج الماش وحسب الطرائق المعتمدة [4] ونسبة الالياف اعتمدت

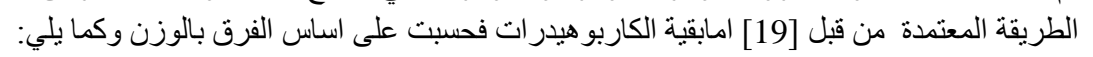

\% الكاربو هيدرات = 100- (البروتين + الزيت + الرماد+الرطوبة + الالياف )

تقدير البروتين الخام

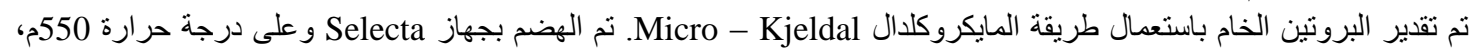

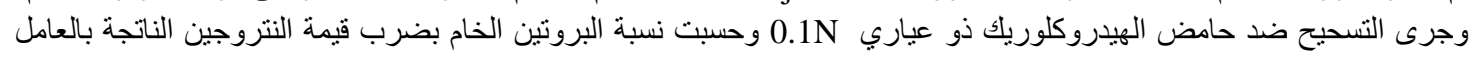
العام 6.25.

تقدير نسبة الزيت تم تقدير نسبة الزيت بجهاز الاستخلاص المستمر Soxhlet apparatus. وضع النموذج المطحون في كثتبان الاستخلاص السليلوزي

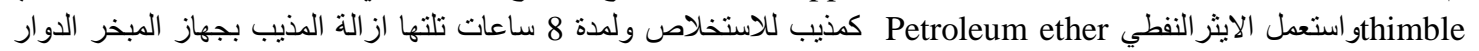
نوع تحت الضغط المخلخل عند درجة حرارة 50م وبعد الوزن تم حساب النسبة المئوية للزيت في النماذج. تقاير الرماد تم تقدير الرماد في النماذج بحرق وزن غراد ام واحد من النموذج في فرن الترميد نوع Lab tech وبدرجة حرارة 550م لمدة ساعتنين

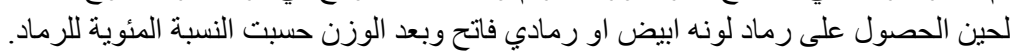

تقدير نسبة الرطوية

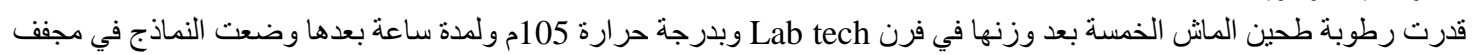

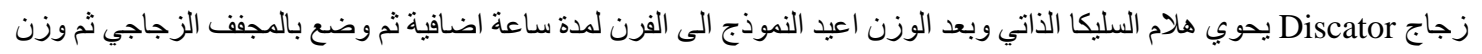

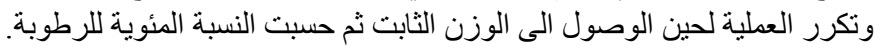

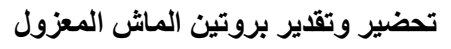

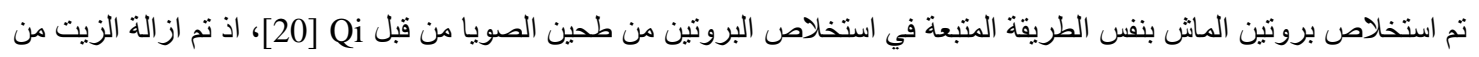

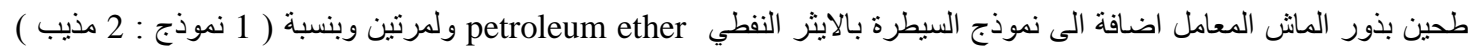

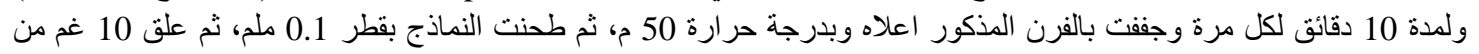

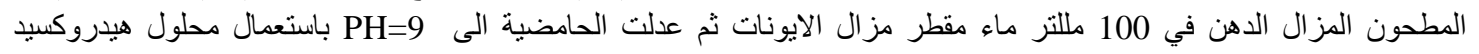

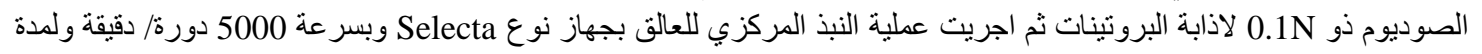

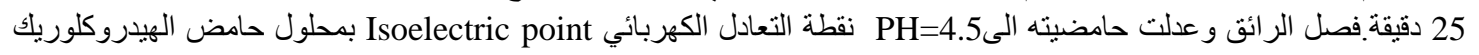

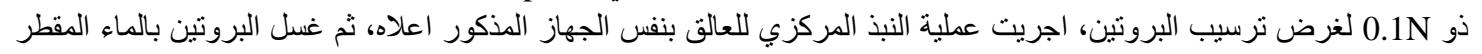

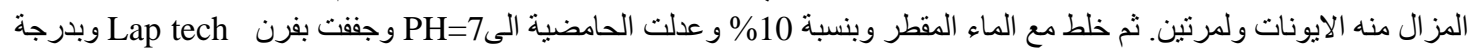

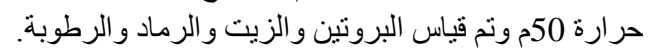

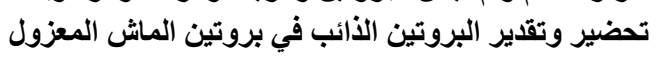

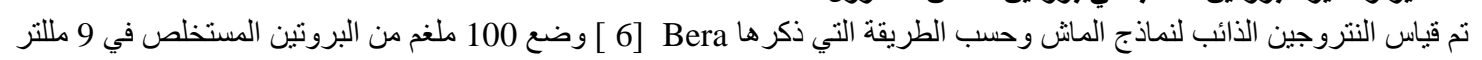

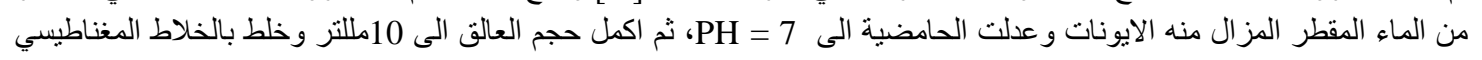

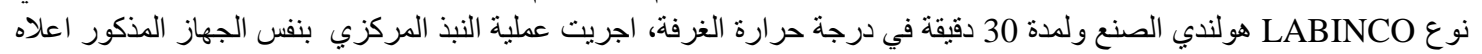

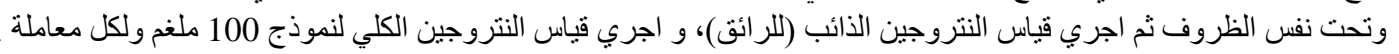

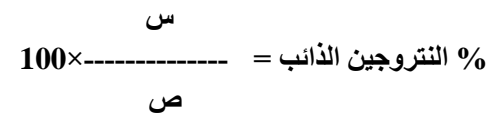

س = النتروجين الذائب للرائق (ملغم ) ص=النتروجين الكلي (100ملغم)نموذج 
x6.25 بروتين الذائب = النتروجين الأبئب قياس درجة التحلل

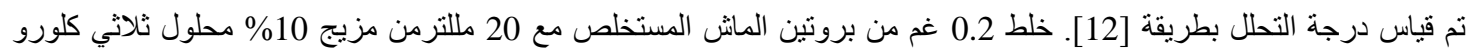

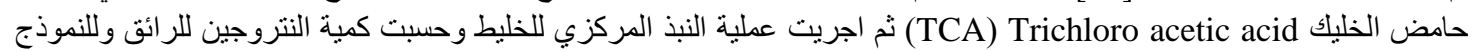
الكامل كلا على حدة. ثم قدرت درجة التحلل وفق المعادلة :-

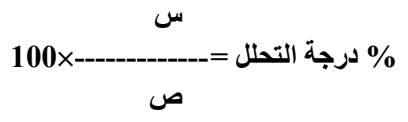

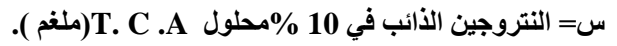
ص= النتروجين الكلي ( ملغر) التحليل الاحصائي:

تم تحليل نتاج التجربة باستخدام البرنامج الاحصائي . SAS- system. وتمت المقارنة بين المتوسطات باستعمال اختبار LSD عند التبار مستوى معنوية النتائج والمناقشة معنة

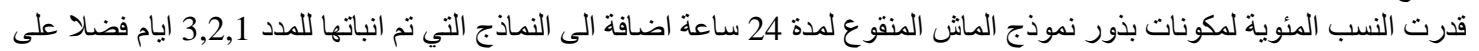

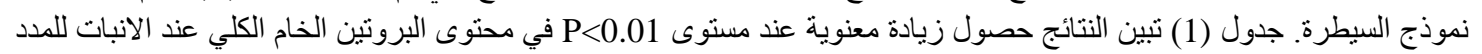

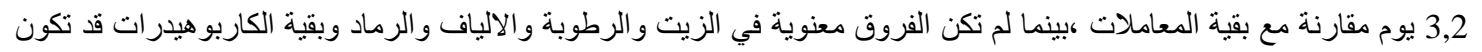

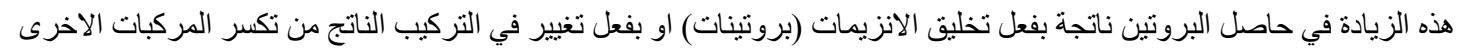

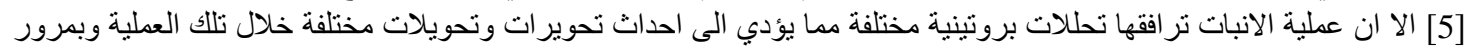

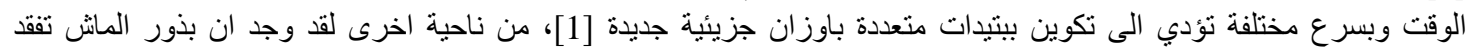

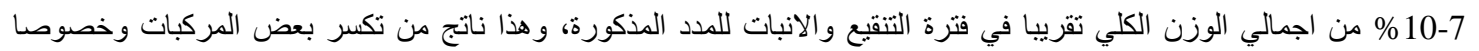

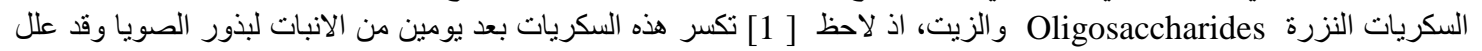

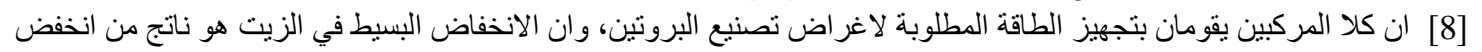

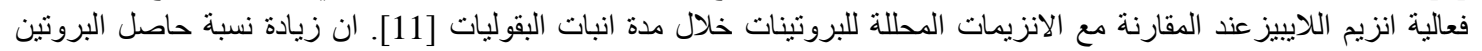

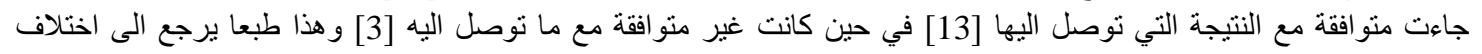

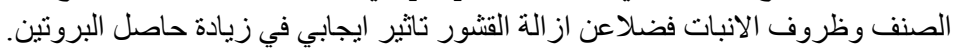

\begin{tabular}{|c|c|c|c|c|c|c|}
\hline \multirow[t]{2}{*}{ L.D.S $(\mathbf{P}<0.01)$} & & لانبات (يوم & ور الماش & التثقيع التابع & السيطرة الابجات & جدول (1): تأثير \\
\hline & ثلاثة & اثنان & واحد & التنقيع & السبطرة & المكونات \\
\hline 1.51 & ab 25.0 & a 25.29 & abc 24.69 & $\begin{array}{c}C \\
23.41\end{array}$ & $\begin{array}{c}\text { C } \\
23.53\end{array}$ & البروتين \\
\hline N.S & 1.73 & 1.75 & 1.79 & 1.90 & 1.83 & الزيت \\
\hline N.S & 2.98 & 3.02 & 3.26 & 3.49 & 3.11 & الرماد \\
\hline N.S & 7.38 & 7.61 & 7.31 & 7.30 & 7.50 & الرطوبة \\
\hline N.S & 17.68 & 17.20 & 17.40 & 17.34 & 17.14 & الالياف \\
\hline N.S & 45.23 & 45.13 & 45.55 & 46.56 & 46.89 & كريوهيدرات \\
\hline
\end{tabular}

يوضح جدول (2) تاثير التنقيع و الانبات في حاصل بروتين الماش المعزول وخاصيتي البروتين الذائب ودرجة تحلله ،و عند المقارنة مع بـاني

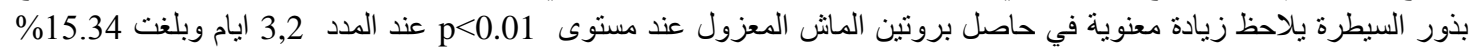

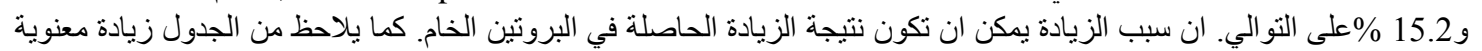

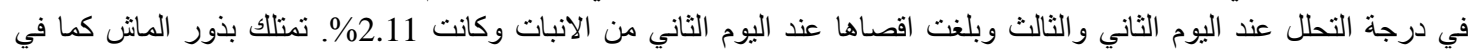

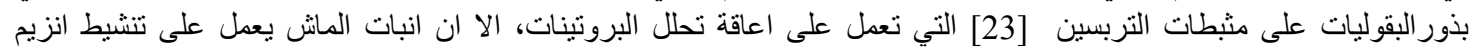
Protienase انزيم Viclin - endopeptidase الذي يعد واحد من هذه الانزيمات التي تعمل على تحلل جزيئات البروتين جزئي التيا وتكوين بيتيدات

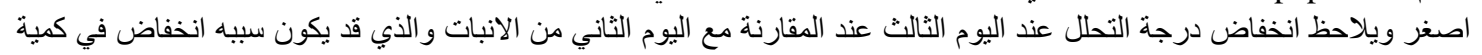

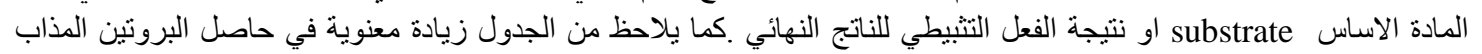

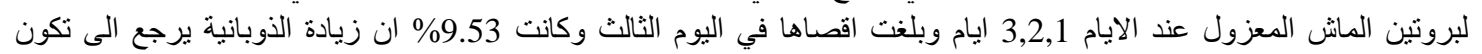

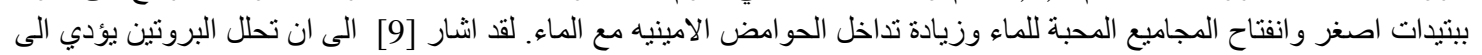

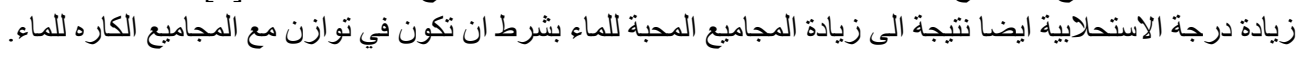




\begin{tabular}{|c|c|c|c|c|c|c|}
\hline \multirow[t]{2}{*}{ L.D.S $(\mathrm{P}<0.01)$} & \multicolumn{3}{|c|}{ مدد الانبات (يوم ) } & \multirow[t]{2}{*}{ التنقيع } & \multirow[t]{2}{*}{ السيطرة } & \multirow[t]{2}{*}{ المكونات } \\
\hline & ثلاثة & اثثان & واحد & & & \\
\hline 1.04 & $15.20 \mathrm{a}$ & $15.34 a$ & $13.65 b$ & $12.80 \mathrm{~b}$ & $12.85 b$ & المعزول البروتين \\
\hline 0.15 & 2.01ab & $2.11 \mathrm{a}$ & $1.91 \mathrm{~b}$ & $1.53 \mathrm{C}$ & $1.40 \mathrm{C}$ & درجة التحلل \\
\hline 1.75 & $9.53 \mathrm{a}$ & $9.09 \mathrm{a}$ & $6.52 \mathrm{~b}$ & $1.95 \mathrm{C}$ & $1.50 \mathrm{C}$ & البروتين الذائب \\
\hline
\end{tabular}

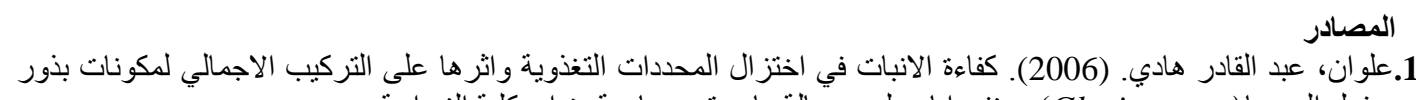

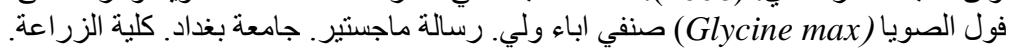

2. Afify, A.L and M. Shousha. (1988). Effect of low dose irradiation on soy protein pattern separated by polyacrylamide gel electrophoresis . J Agric Food Chem. 36:810-813.

3. Aman, P. (1979). Carbohydrates in raw and germinated seeds from mung bean and chick Pea. J. Sci. Food Agri.10: 869-875.

4. Association of official analytical chemists (A.O.A.C). (1984). Official methods of analysis $14^{\text {th }}$ ed. Washington. D.C.

5. Bau, H.M., Villuame, C., Nicolas, J. and Mejean, L. (1997). Effect of germination on chemical composition, Biochemical constituents and anti -nutritional factors of soy bean ( Glycine max ) seeds . J. Sci. Food Agric.73:1-9.

6. Bera, M.B. and Mukherjee, R.K. (1989). Solubility, emulsifying and Foaming properties of rice bran protein concentrates .J.Food .Sci. 54:142-145 .

7. Calderon, A.M., Ruis, S.R.A and Java, M.E. (2000). Enzymatic hydrolysis and functional properties. J.Food Sci. 65 (2) :246-252 .

8. Chandrasiri,V., Bau, H.M., Vllaume, C., Ciannangeli, Lorient, F. and Mejean, L. (1987). Effect de la germination de la graine de sojasur La composition et la valeurnutritionnelle de safarine. Science des Aliments. 7 ( horseserie ): 139-150.

9. Chobert, J.M., Bertrand-Harth,C., and Nicolas, M,G. (1988B). Solubility and emulsifying properties of casein and whey protein modified by trypsin .J Agri.Food Chem. 36:883-892.

10. Damodaran, S. (1994). Structure-function relationship of food protein in protein functionality in food system, N.S. Hettiarachchy and G.R. Ziegler. (Ed.).pp. 1-37. Marcel Dekke, New York.

11. Elham,W., Godfrey, H.P and Mihael,G.P. (1988). Protease digestion of the meals of ungerminated and germinated soy beans J. Sci. Food Agric. 44:201-21.

12. Kim, S.Y., Peter, S.W and Rhee, K. (1990). Functional properties of proteolytic enzyme modified soy protein isolate. J. Agric. Food Chem. 38:651-656.

13. Kylen, A.M. and Mccready, R.M. (1975). Nutrients in seeds and sprouts of alfalfa, lentils alfalfa, and mung beans. J. Food Sic. 40:1008-1009.

14. Lah, Cl. and Cheryan, M. (1980). Protein solubility characteristics of and ultra -filtered full- fat soy bean product. J. Agri. Food Chem. 28:911-6. Modified soy proteins and ficin tenderized meat on the quality attributes of sausage .J. Food Sci.68:85 -88.

15. Lin,Y.H. and Yao,W. (1996). Mung bean (Vigna radiate L.Wilezek) containssome high proteolytic activities already before germination . Bot. Ball. Acad.Sin.37

16. Lin, SB., Chiang, WD., Cordle, C.T and Thomas, R.L. (1997). Functional and immunological properties of casein hydrolysate produce from two-stage membrane system. J. Food Sci. 62:480.

17. Liu, K. (2001). Soy bean chemistry, Technology and utilization. ITP. International Thomson Publishing. Chapman \& Hall book.

18. Lozano, P. and mComba, D. (1992). $\alpha$ - Chemotrypsine in plastein synthesis effect of hydroxylates additives on enzyme activity. Bchem.Biotechno.1.33;51-65.

19. Pearson, D.(1976). The chemical analysis of foods Seventh Edition Churchill Livingston.

20. Qi, M., Hettiarachchy, N.S. and Kalapathy, U. (1997). Solubility and emulsifying properties of soy protein isolates modified by pancreatin. J. Food Sci. 62(6)1110-1115.

21. Ramezani, R., RAMINLARI, M and FALAHI, H. (2003). Effect of Chemically modified soy protiens and ficin tenderized meat on the quality attributes of sausage .J. Food Sci. 68:85 -88.

22. Steel, R.Q.D and Torro, H. (1980). Princples and procedures of statistics. Mc. Graw-Hill, lic.N.Y.

23. Tan-wilson, A.L. Rightmire, B.R. and Wilson, K.A. (1982). Different rates of metabolism of soy bean protienase inhibitors during germination. Plant Physiology.70:493-497.

24. Ziegler, F., Nitenberg, G., Coudray-lucas, C., Lasser p. and Giboudeau, j. L. (1998). Pharma-cokinetic assessment of an oligopeptide-based enteral formula in abdominal surgery patients. Am .j. Clin.Nutr. 67:124-128. 